\title{
Algorithms for crime prediction in smart cities through data mining
}

\author{
Autores \\ Jesús Silva, Ligia Romero, Roberto Jiménez González, Omar Larios, Fanny Barrantes, \\ Omar Bonerge Pineda Lezama, Alberto Manotas
}

\begin{abstract}
The concentration of police resources in conflict zones contributes to the reduction of crime in the region and the optimization of those resources. This paper presents the use of regression techniques to predict the number of criminal acts in Colombian municipalities. To this end, a set of data was generated merging the data from the Guardia Civil with public data on the demographic structure and voting trends in the municipalities. The best regressor obtained (Random Forests) achieves a RRSE (Root Relative Squared Error) of $40.12 \%$ and opens the way to keep incorporating public data of another type with greater predictive power. In addition, M5Rules were used to interpret the results.

Palabras clave

Public data, Data mining, Prediction of facts.
\end{abstract}

